\title{
Relapsing corticosteroid-dependent polyneuritis
}

\author{
W. B. MATTHEWS ${ }^{1}$, D. A. HOWELL, AND R. C. HUGHES ${ }^{2}$ \\ From the Derbyshire Royal Infirmary
}

SUMMARY Three patients are described with chronic polyneuritis of unknown cause in whom as state of corticosteroid dependence developed. A fatal relapse occurred in one patient. No clinicalo electrophysiological, or pathological features were found from which it would have been possible to을 predict this form of response to treatment.

In 1958 Austin described a patient with chronic polyneuritis of unknown cause in whom remission repeatedly and predictably occurred on corticosteroids or corticotrophin, with relapse on stopping treatment or reducing the dose. There has been little systematic attempt to assess the results of treatment of chronic polyneuritis and few subsequent case reports of corticosteroid-dependence of this type. We here describe three further examples.

\section{CASE 1}

(U.H. DRI 260963) A 45-year-old woman first attended hospital in January 1963. Symptoms had begun three months before with increasing symmetrical weakness of the legs and a month later of the arms, the left more than the right. There had been occasional paraesthesiae in the left hand only.

There was no past history of important disease. She had had one normal pregnancy in 1947. There was no exposure to drugs or toxins and no family history of similar disease.

She had a waddling gait and was unable to rise from a chair without using her arms. Facial and bulbar muscles were not involved but there was moderate generalized weakness of the limbs and loss of tendon jerks. Plantar reflexes were flexor. There was no sensory loss. The peripheral nerves were not thickened and were not found to be so at any subsequent examination.

The cerebrospinal fluid protein was $75 \mathrm{mg} / 100 \mathrm{ml}$. with no increase in cells. Full blood count was normal and sedimentation rate was $3 \mathrm{~mm}$ in the first hour. The following investigations were normal: serum proteins, electrolytes, calcium and phosphate, cholesterol, liver function tests, vitamin $B_{12}$, blood urea, faecal fat, urinary hydroxyindoles, and glucose tolerance. Radiographs of the chest and barium meal revealed no abnormality. No LE cells

\footnotetext{
${ }^{1}$ Present address: the Manchester Royal Infirmary.
}

2Present address: Newcastle General Hospital. were present in the peripheral blood. The urine was normal.

Treatment with prednisolone $30 \mathrm{mg}$ a day was begun? on 21 January 1963. Subsequent dosage and the clinica state are shown in Fig. 1. An increase in strength waso noted two weeks from the beginning of treatment and after six weeks an attempt at stopping treatment was followed by a relapse in which walking unaided difficult. The dose was increased with some furt疋 improvement but treatment was stopped in July 1963 त्. she was extremely moon faced. There was little change in her condition until April 1964 when weakness increased and for the first time sensory loss was found, consistigng of slight changes to light touch in the hands. She readmitted in May 1964 with severe generalized weakness of the limbs. The cerebrospinal fluid (CSF) protein now $100 \mathrm{mg} / 100 \mathrm{ml}$. Prednisolone $30 \mathrm{mg}$ a day was begun and continued in a lower dose. Improvement was notec5 three weeks later and was maintained until December 1964 when, while on $10 \mathrm{mg}$ prednisolone a day, there was a severe relapse. The dose was immediately increased ton $40 \mathrm{mg}$ a day but was difficult to maintain at this leve because of extremely marked hypercorticoidism. On $20 \mathrm{mg}$ a day no improvement occurred.

From the onset of the disease she had suffered from 'attacks'. At first she described these as palpitation and flushing and little attention was paid to them, but in relapses of the polyneuritis - and particularly in that of December 1964 and thereafter-these symptoms were increasingly obtrusive. They would occur at least once af day and at this time consisted of sinus tachycardia up tog 140 per minute, dyspnoea, flushing, tremor of the hands. and blepharospasm, lasting up to 15 minutes and causingo severe distress. In spite of the obvious evidence of organic disease, it was thought possible that these symptoms were? psychogenic and accordingly an identically appearing placebo was gradually substituted for prednisolone and on 27 January 1965 the latter was stopped. At this point marked generalized weakness of the limbs was stilf present but she was able to walk. The attacks continued. On 10 March 1965 she was admitted with severe generalized weakness, the legs being almost paralysed and speech $\omega$ 330 


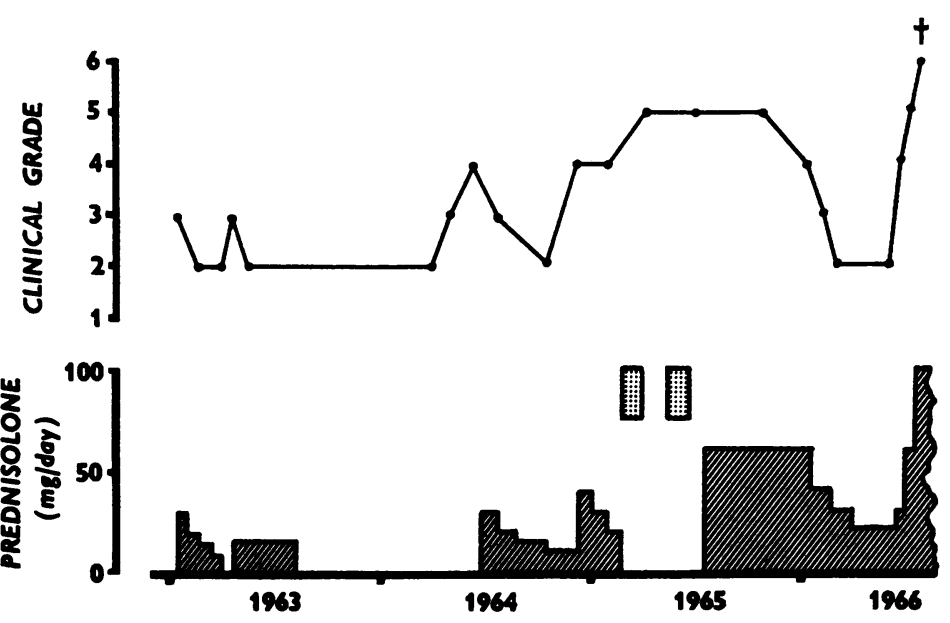

FIG. 1. Clinical course in case 1. Clinical grading in this and subsequent figures: 0 , normal; 1, slight signs without disability; 2, slight disability; 3 , moderate disability, unable to work, restricted house work; 4, walking with difficulty; 5 , severe paralysis, bedridden; 6 , critically ill. Courses of 6-mercaptopurine indicated by dotted shading. and swallowing being affected for the first time. In this helpless condition she continued to have paroxysmal symptoms in which the head nodded violently and the trunk rocked to and fro, the eyes being tightly closed. A mottled flush of the neck and chest would appear with dermatographia in the same area. The pulse rate would rise to 120 /minute.

An increase in the dose of prednisolone to $30 \mathrm{mg}$ a day had no effect. A course of 6-mercaptopurine $25 \mathrm{mg}$ twice a day for four weeks was also ineffective. In May 1965 wasting of the hand muscles was noted and distal cutaneous sensory loss found in all limbs. In June 1965 she was transferred to the care of Professor R. Gilliatt at the National Hospital, Queen Square. The CSF protein was now $150 \mathrm{mg} / 100 \mathrm{ml}$. A further course of 6-mercaptopurine was not helpful. The dose of prednisolone was raised to $60 \mathrm{mg}$ a day and this was maintained on her readmission in Derby on 21 June 1965. A month later improvement was first noted and continued slowly until the end of the year. In the next two months increase in strength was rapid and she became fully active, doing all her own housework and able to climb stairs and to go shopping. The 'attacks' had stopped. Her appearance was grotesquely distorted by the high corticosteroid dosage and from 12 January 1966 it was gradually reduced, reaching $10 \mathrm{mg}$ a day on 20 April 1966 at which time the only weakness was slight bilateral foot drop. A month later, on the same dose, she rapidly deteriorated and was admitted with severe paralysis. Attempts to control this with doses of prednisolone of 20 to $60 \mathrm{mg}$ a day were unavailing and respiratory weakness developed. Hydrocortisone $400 \mathrm{mg}$ a day by intravenous injection was added to the regime and a tracheostomy was done but she died on 23 June 1966.

It was concluded that moderate doses of prednisolone produced moderate improvement. Severe relapse eventually appeared to respond to prolonged higher dosage but attempts at reduction were followed by fatal relapse, uninfluenced by corticosteroids in dosage probably too small to be effective.

\section{CASE 2}

(J.E. D.R.I. 270029) This man was born in 1903. He had no past history of important disease and took no drugs. He did not drink alcohol or smoke. He worked in a china works but had no contact with lead.

His symptoms began in February 1963 with tingling in the fingers of both hands and in the insteps. He had slight difficulty in picking up small objects and the tips of the fingers felt sore and numb. He first attended hospital in September 1963 when reduction of touch and pain sensation at the tips of all the fingers was noted. The tendon jerks were normal and there was no weakness. By April 1964 the sensory symptoms and signs had increased and had spread to the lower limbs. In July 1964 weakness of the hand muscles was first noted but the tendon jerks were still present. Weakness gradually increased and the paraesthesiae assumed an unpleasant burning character. He was admitted in December 1964.

Distal weakness was now present in all limbs and cutaneous sensation was reduced below the wrists and the mid-calf and also over an area on the anterior aspect of the neck and beneath the chin. There was no facial weakness or involvement of bulbar muscles. The superficial nerves of the cervical plexus and those on the feet were enlarged but the palpable nerve trunks were normal. The ankle jerks and triceps jerks were absent.

The CSF protein was $40 \mathrm{mg} / 100 \mathrm{ml}$. and was never subsequently found to be raised. The blood count, ESR, serum proteins, electrolytes, blood urea, and blood sugar were normal and WR negative. Radiographs of the chest were normal.

Prednisolone $30 \mathrm{mg}$ a day was begun in December 1964 (Fig. 2) and continued as a maintenance dose of $15 \mathrm{mg}$ a day, reduced after three months to $7.5 \mathrm{mg}$ because of hypercorticoid symptoms. Moderate improvement in strength occurred but the remaining tendon jerks were lost and in May 1965 tremor of the hands was first noted. This was almost regular at around $6 / \mathrm{sec}$, accentuated when the hands were outstretched when it took the form of 


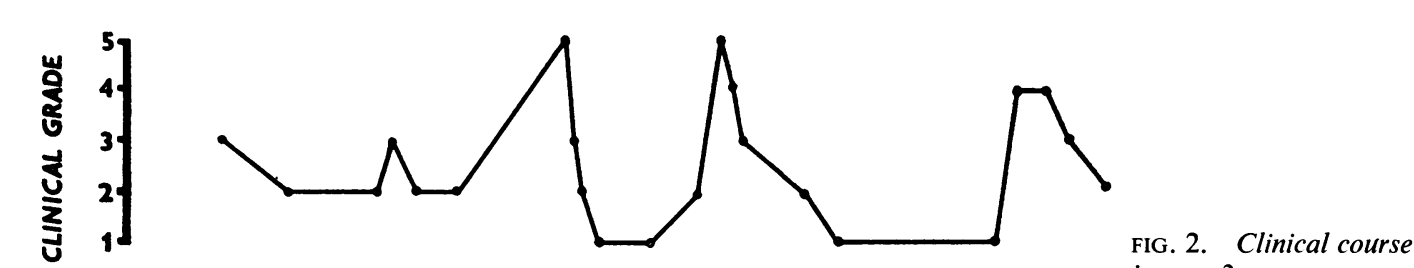
in case 2 .

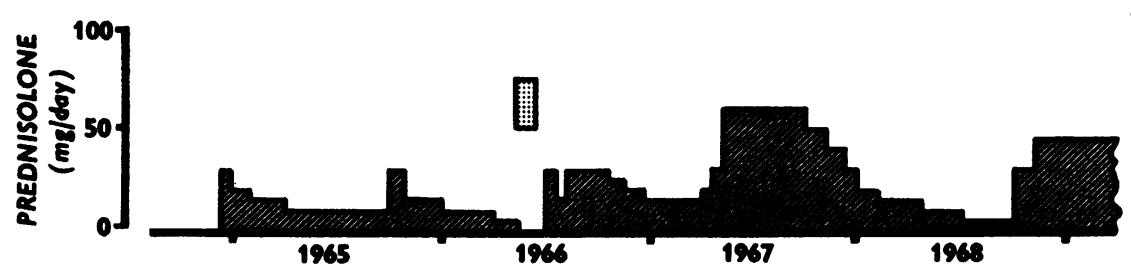

flexion and extension at the wrists and metacarpophalangeal joints. Tremor was also present at rest and was then indistinguishable from the 'pill rolling' of Parkinson's disease. There was no rigidity.

In August 1965 there was a slight decline in strength which improved on an increased dose of prednisolone. In March 1966 a slow deterioration was observed increasing until his admission in May. Prednisolone was stopped but a course of 6-mercaptopurine $25 \mathrm{mg}$ twice a day for four weeks was accompanied by accelerated weakness. By the end of June, on prednisolone $15 \mathrm{mg}$ a day he was unable to walk and was virtually helpless. The dose was increased to $30 \mathrm{mg}$ a day and a wheel chair ordered but a month later he walked into the clinic unaided. This dose was maintained and in September 1966 he returned to work. Strength was normal, although slight cutaneous sensory loss was detectable at the tips of the fingers. The dose of prednisolone was slowly reduced to $15 \mathrm{mg}$ a day and he remained well with return of the knee jerks noted in January 1967. Tremor of the hands was still present and the median and ulnar nerves were now thickened and firm but not tender.

The next relapse began in March 1967 while still on $15 \mathrm{mg}$ prednisolone a day. The dose was increased to $30 \mathrm{mg}$, which had proved effective in the preceding relapse, but within three weeks of the first symptom of relapse he was unable to stand. Distal sensory loss spread up the limbs. He complained of double vision, although no ocular palsy was found. There was no facial, bulbar, or respiratory weakness but he was bedridden and helpless. The blood pressure rose from previously normal levels to $180 / 130 \mathrm{~mm} \mathrm{Hg}$. The dose of prednisolone was increased to $60 \mathrm{mg}$ a day and improvement was noted within two weeks. On this higher dose his strength steadily increased and by July only slight weakness was detectable. At that time he developed symptoms of diabetes, which was with difficulty controlled with chlorpropamide, phenformin, and restricted carbohydrate intake. His face was much distorted by the steroid effect and the blood pressure remained high. He returned to work in August 1967.

Because of the severe side-effects, the dose of prednisolone was cautiously reduced in the course of several months. By November 1967, on $30 \mathrm{mg}$ a day, tremor was no longer present. In January 1968 all tendon jerks were present and strength and sensation were normal, although the nerve trunks were still hypertrophied. In February the patient announced that he could ride a bicycle up hill and in April the diabetes was controllable by dietary restriction alone and the patient felt normal. The dose of prednisolone was reduced gradually to $5 \mathrm{mg}$ a day byo July 1968. Remission continued until September whe weakness again increased, the tendon jerks were lost, an $\bar{P}$ tremor returned. Prompt increase to $45 \mathrm{mg}$ a day appeare $\varnothing^{\circ}$ to arrest his deterioration but complete remission did nof occur.

It was concluded that this chronic sensory-moto polyneuritis with tremor and hypertrophy of nerves showe ed repeated remission on increasingly large doses of prednisolone followed by relapse when treatment was reduced because of intolerable side-effects.

\section{CASE 3}

(G.W. DRI 265741) In April 1967 at the age of 59 this woman developed tingling in the fingers and toes. These gradually increased and in July she began to fall down and found that she was unable to step on to a bus or to lift her arms to comb her hair. She was admitted in August 1967. There was no past history of important disease and no family history of polyneuritis.

There was no weakness of muscles supplied by the cranial nerves but she was short of breath on slight exertion. Severe weakness was present in the upper limbs, particularly of proximal muscles, the lower limbs being similarly but less severely affected. She was able to walk but could not rise from a chair without help. The tendon jerks were absent. No sensory loss was detected.

The CSF protein was $40 \mathrm{mg} / 100 \mathrm{ml}$. with no increase in cells. The following investigations were normal: radiograph of chest, full blood count, serum electrolytes, proteins, cholesterol and $\mathrm{B}_{12}$, and blood urea. The ESR was $18 \mathrm{~mm}$ in the first hour. No LE cells were present in the peripheral blood. WR was negative.

Barium meal showed a hiatus hernia. The urine was infected with $E$. coli. Fasting blood sugar was $83 \mathrm{mg} / 100$ 
ml. and after $50 \mathrm{~g}$ glucose orally levels of $180,280,290$, and $180 \mathrm{mg} / 100 \mathrm{ml}$. were obtained at 30 minute intervals, glucose being present in the urine at one hour.

In view of the abnormal glucose tolerance she was treated with chlorpropamide $100 \mathrm{mg}$ a day and restricted carbohydrate. Blood sugar levels were immediately controlled but weakness rapidly increased and by 9 September 1967 she was almost helpless, although no respiratory weakness developed. On this date prednisolone $\mathbf{4 0} \mathrm{mg}$ a day was begun (Fig. 3) and five days later the distal muscles of the arms were noted to be stronger. By 14 September 1967 she could feed herself and on 20 September 1967 she walked with help. Rapid improvement continued on a reduced dose of prednisolone and by November there was no weakness or sensory loss and the knee jerks had returned. A month later the dose was reduced to $2.5 \mathrm{mg}$ a day but paraesthesiae returned and within two weeks there was again marked generalized limb weakness and distal sensory loss. She was readmitted and the dose was increased to $40 \mathrm{mg}$ a day with slight improvement, but notable increase in strength did not occur until the dose was raised to $60 \mathrm{mg}$ a day.
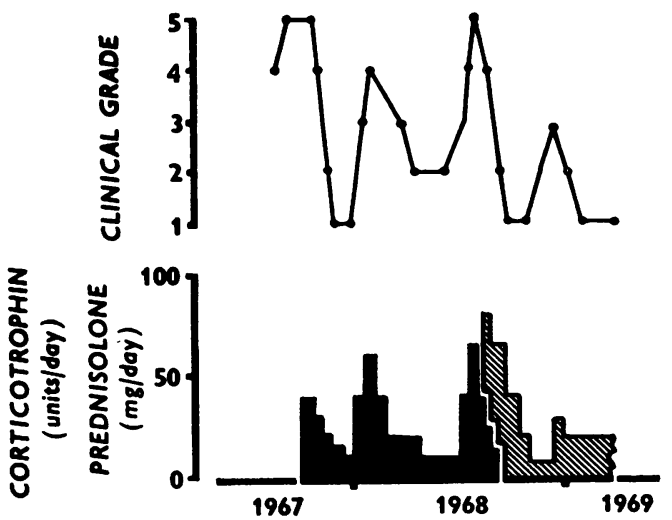

FIG. 3. Clinical course in case 2. Solid shading, prednisolone; hatched, corticotrophin.

This dose could not be maintained as she developed severe upper abdominal pain, not improved by using enteric coated capsules, intermittent glycosuria, severe moon-face and an attack of pneumonia largely concealed by the corticosteroid therapy. Complete recovery of strength did not occur but there was considerable improvement. The dose was reduced to $7.5 \mathrm{mg}$ a day in April 1968 but some toxic symptoms persisted. In June 1968 while on this dose she relapsed and within the course of 10 days again became bedridden. The dose was increased to $60 \mathrm{mg}$ a day but an additional side-effect occurred, consisting of exceedingly severe headache on the slightest exertion. She was very weak and distressed by abdominal pain. Lumbar puncture was repeated and showed a pressure of $120 \mathrm{~mm} \mathrm{CSF}$ and a protein of $35 \mathrm{mg} / 100 \mathrm{ml}$. in the CSF. Corticotrophin 40 units twice a day was added to the treatment and the prednisolone was reduced and stopped in the course of three weeks.
The headaches and abdominal pain subsided and strength improved. In the succeeding eight months her condition fluctuated, apparently in close relation to the dose of corticotrophin. Increased weakness could be relieved by 30 units a day and in February 1969, after a month's such treatment, there was almost complete clinical remission. This dose caused exacerbation of the diabetes and severe distortion of the face.

The polyneuritis in this case, therefore, responded repeatedly to prednisolone in increasing doses but intolerable side-effects led to reduction of dosage and relapse. Corticotrophin was also effective and less toxic.

\section{FURTHER FINDINGS: CASES 1, 2, 3}

NERVE CONDUCTION

Nerve action potentials could seldom be obtained. A potential was recorded from the ulnar nerve at the elbow when stimulating the fifth digit in case 1 at a time when she had sensory symptoms but no sensory loss. Later in the disease no potential could be recorded and none was found at any stage in cases 2 and 3.

Motor conduction velocity was much reduced. In cases 1 and 3 fluctuations in the clinical state did not appear to influence the progressive decline in velocity (Table 1). In case 2 serial recordings were made over four years. In short-lived remissions conduction velocity altered little but sustained improvement occurred during the prolonged remission of 1967-68, although completely normal figures were not obtained even when motor power had been normal for several months (Fig. 4.)

\section{TABLE 1}

CONDUCTION VELOCITY AND TERMINAL LATENCY IN THE RIGHT ULNAR NERVE IN CASES 1 AND 3

\begin{tabular}{ccccc}
\hline Date & $\begin{array}{c}\text { Proximal } \\
(\mathrm{m} / \mathrm{sec})\end{array}$ & $\begin{array}{c}\text { Distal } \\
(\mathrm{m} / \mathrm{sec})\end{array}$ & $\begin{array}{c}\text { Terminal } \\
(\mathrm{msec})\end{array}$ & $\begin{array}{c}\text { Clinical } \\
\text { grade }\end{array}$ \\
\hline
\end{tabular}

Case 1

21 January 1963

5 February 1963

26 March 1963

26 January 1965

30 March 1965

$\begin{array}{llcl}58 & 27 & 4 \cdot 5 & 3 \\ 45 & 32 & 5 & 3 \\ 32 & 30 & 4 \cdot 2 & 2 \\ 22 & 20 & 8 & 4 \\ 20 & 18 & 10 & 5\end{array}$

Case 3

22 August 1967

26 September 1967

16 January 1968

2 July 1968

25 October 1968

$\begin{array}{ll}36 & 30 \\ 23 & 20 \\ 10 & 20 \\ - & 21 \\ - & 22\end{array}$

\begin{tabular}{rr}
7 & 5 \\
7 & 4 \\
9 & 4 \\
10 & 2 \\
8 & 2 \\
\hline
\end{tabular}

Pathology. A full necropsy performed on case 1 showed that she died of bronchopneumonia. No cancer was found in any organ and there was no evidence of any systemic disease.

The brain was macroscopically and microscopically normal. In particular there was no lesion in the basal ganglia or cerebellum that might be thought responsible for her involuntary movements. The cervical spinal cord showed some pallor in the posterior columns in sections stained for myelin. The anterior horn cells were normal at all levels examined. 


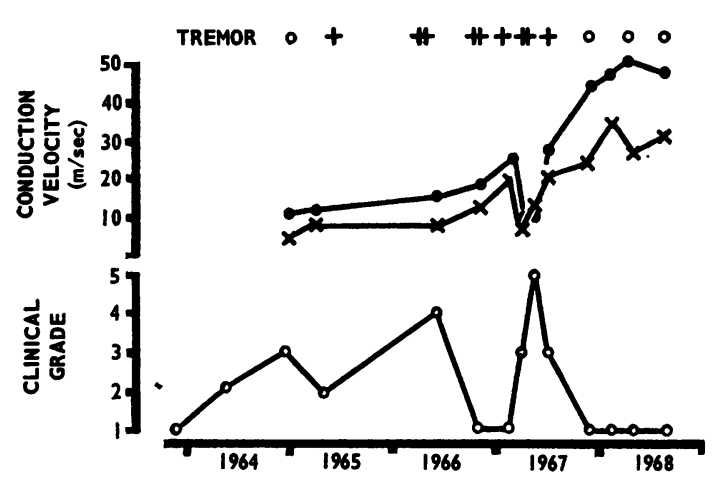

FIG. 4. Open circles, clinical grade; closed circles, motor conduction in proximal sector of right ulnar nerve; crosses, distal sector.

The right brachial plexus, the main nerve trunks in the upper arm, and the median nerve in the forearm and right tibial nerves were sectioned. Changes were least marked in the nerve roots but more peripherally the abnormalities were uniformly distributed. Axons appeared normal. In cross-sections myelin sheaths were numerous but thin. Single fibre preparations stained with osmium tetroxide showed great variation in segmental length and in thickness of the myelin sheath. The epineurium and perineurium were not thickened.

Large quantities of amorphous material were found to be distending the perineurium and often separating the individual nerve fibres (Figs 5 and 6). Muscle spindles contained and sometimes appeared to be distended by similar material lying between the capsule and the endomysium of the intrafusal fibres (Fig. 7).
In a biopsy of the sural nerve obtained from case 3 fourô months after the onset of symptoms little abnormal was $Z$ seen. A small amount of amorphous material was $\underset{\complement}{\complement}$ present within the perineurium. Occasional large fibres with thin myelin sheaths were seen but there was no? obvious loss of axons or myelin. In case 2 the sural nervee biopsy was obtained much later in the disease. Axons 0 appeared normal but myelin sheaths were scanty. The epineurium and perineurium were not thickened. The $\frac{\rho}{3}$ perineurium was distended with eosinophilic material surrounding and separating individual fibres.

In all nerves examined some of the epineural and perineural vessels were surrounded by small round cellso with little visible cytoplasm, presumably small lympho-o cytes. This finding varied in intensity, being most marked $\frac{}{0}$ in case 3, and was no more obvious in the main nerve $\overline{\bar{c}}$ trunks in case 1 than in the sensory nerve biopsies from $\overrightarrow{\mathbb{Q}}$ the other two patients.

The staining properties of the abnormal amorphous material were examined but were conflicting. Most of the material was eosinophilic, but occasionally colourless, $\stackrel{\circ}{-}$ and stained brown with haematoxylin and van Gieson's $\vec{\omega}$ stain. It did not stain for amyloid with Congo red or Highman's crystal violet. There was no brown metach-כ romasia with toluidine blue. It did not stain with periodic acid-Schiff or Southgate's mucicarmine. In biopsy $\omega_{\text {}}$ specimens from cases 2 and 3 the material stained with $\omega$ alcian blue suggesting the presence of an acid mucopo $-\dot{\omega}$ saccharide but confirmation from other stains lacking. In case 1 , where much larger quantities क्षf 0 material were available, alcian blue-positive materai $=$ was scanty and confined to the periphery of a few fascicle. The material had been fixed in formalin for a number of $\subseteq$ years before the examination was completed and was not $\overparen{D}$ suitable for more definitive histochemical techniques.

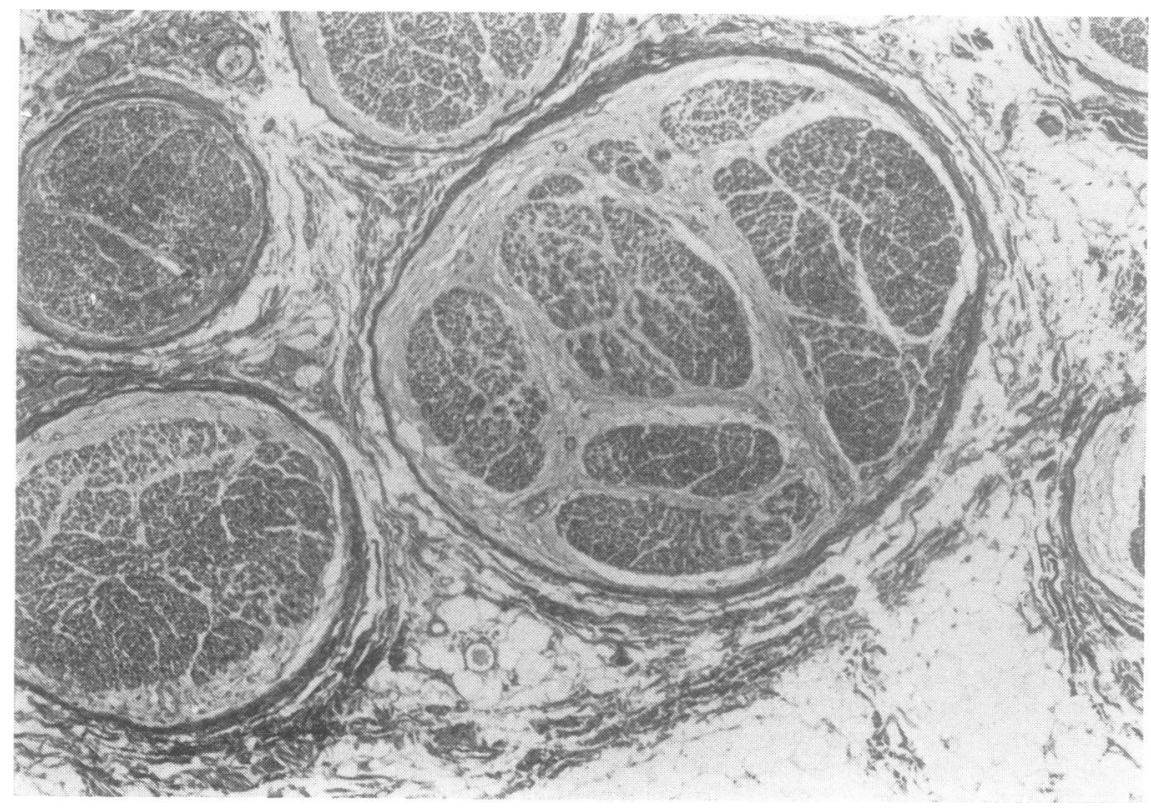

FIG. 5. Transverse section of the right brachial plexus in case 1 showing amorphous material within the perineurium. $H$ and $E, \times 30$. 


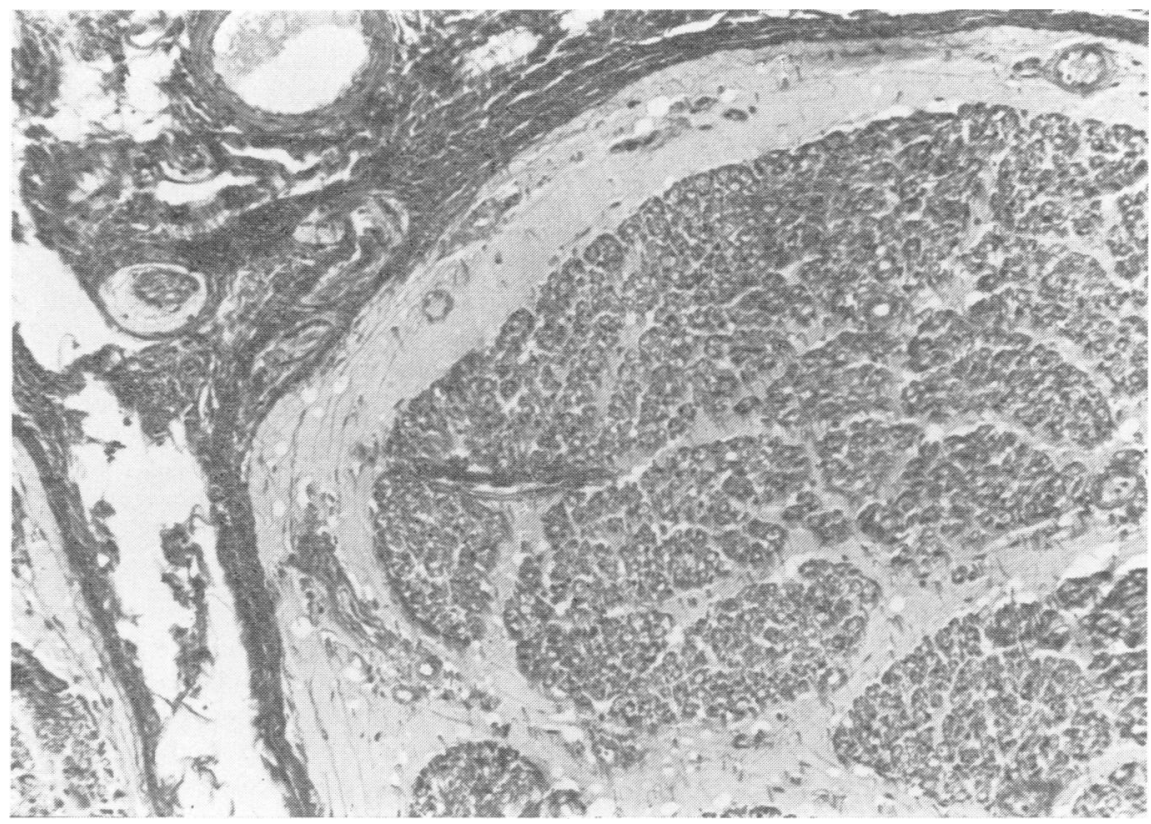

FIG. 6. Transverse section of brachial plexus. $H$ and $E, \times 75$.

INVOLUNTARY MOVEMENTS Tremor was a prominent symptom in case 2 and complex paroxysmal movements accompanied by autonomic changes and great distress occurred in case 1 . The nature of these movements could not be determined but investigation of tremor in polyneuritis is proceeding. In both patients the movements were absent during remission of the polyneuritis.

\section{DISCUSSION}

In the majority of cases of both acute and chronic polyneuritis no cause or recognized clinical association can be found. The distinction between acute idiopathic polyneuritis and chronic forms of unknown cause must therefore be made on clinical

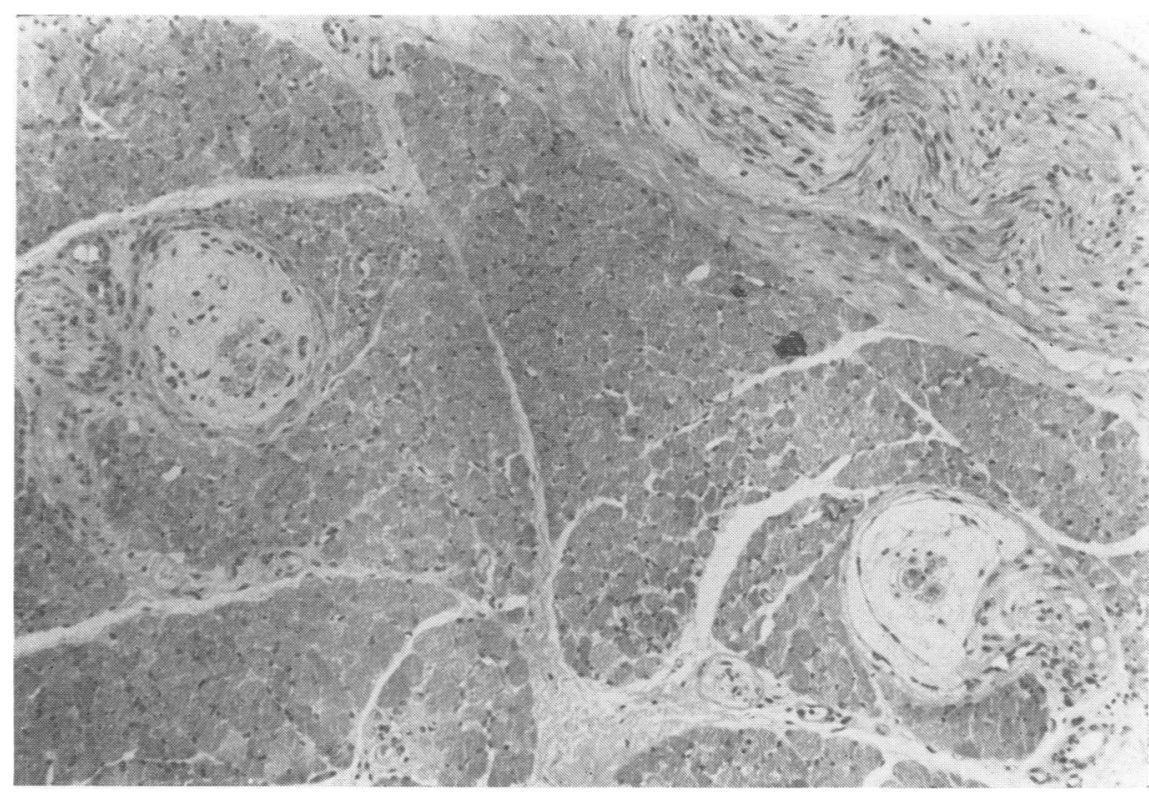

FIG. 7. Section of the right thenar eminence in case 1 showing similar material within muscle spindles. $H$ and $E, \times 75$. 
features alone, primarily the duration of the progressive stage of the disease. In published series of the Guillain-Barré syndrome this stage has lasted for less than 21 days in a high proportion of cases (Ravn, 1967), but at no point is it possible to divide the acute from the chronic form except by arbitrary decision (Matthews, 1952). Facial palsy is uncommon in chronic cryptogenic polyneuritis (Barraine, 1965) and the protein level in the cerebrospinal fluid is often normal, as in two of the present cases, but these distinctions are inconstant. Thickening of nerve trunks is not confined to chronic polyneuritis but may occur in acute attacks (Nattrass, 1921). In addition to these difficulties in making a valid clinical distinction between acute and chronic forms there is growing evidence of a continuing disease process in the Guillain-Barré syndrome, even when complete clinical recovery may have occurred. Relapse and recurrence are well known (Jean, 1959). Asbury, Arnason, and Adams (1969) have found perivascular lymphocytic infiltration in peripheral nerves at necropsy many years after full clinical recovery from acute idiopathic polyneuritis. Hinman and Magee (1967) found that the cerebrospinal fluid protein levels might remain elevated for eight years after similar recovery. The distinction between acute and chronic forms is therefore even less tenable and it is possible that the disease process may be the same throughout the wide spectrum but with marked variation in severity and duration of clinical expression.

The value of corticosteroid treatment in acute polyneuritis is still uncertain, largely because the natural outcome of the untreated disease is recovery in a high proportion of cases. It is now impossible to obtain a clear idea of the course of chronic cryptogenic polyneuritis untreated with corticosteroids. A chronic course characterized by remission and relapse is well documented from before the advent of corticosteroids (Jean, 1959) and it is also known that such cases may be entirely uninfluenced by treatment (Ashworth and Smyth, 1969). There appears to be no modern clinical and pathological description of chronic polyneuritis of unknown cause progressive without remission to a fatal outcome. The recognition of a therapeutic effect therefore presents formidable difficulties and the occurrence of single remissions clearly cannot be regarded as significant. The state of corticosteroid dependence may be defined as the apparent production of three or more remissions with relapse on reduction of the dose, in the absence of recognizable spontaneous remission. In no published report has dependence been so clearly demonstrated as in Austin's original case (Austin, 1958) and there are few detailed descriptions fulfilling these criteria, only those of Jean (1959, case 1), Martin and $\frac{\text { O }}{Z}$ Philippart (1962, case 3), Barraine (1965, case 31), and Thomas, Lascelles, Hallpike, and Hewer (1969, case 4) being acceptable. Castaigne, Brunet, and Nouailhat (1966) recognized corticosteroid de pendence in nine out of 24 patients with relapsing ${ }_{\mathscr{C}}^{\top}$ polyneuritis, including the case of Barraine, but $\curvearrowright$ gave no detailed description.

Of the present cases the response to treatment in case 1 was never as rapid as in Austin's (1958) patient and dependence does not seem to have been immediately established, but the eventual speed ando severity of relapse on reduction of dose left no doubt of the efficacy of corticosteroids. In cases 2 and $3 \overline{\bar{\alpha}}$ improvement on treatment or on increasing the dose $ه$ was more rapid and relapse on reduction equally impressive. The management of these patients was ${ }^{\infty}$ exceedingly diffizult. In case 1 moderate cortico- $\vec{\circ}$ steroid dosage produced moderate improvement with $\overrightarrow{-}$ relapse when the dose was reduced or stopped ${ }_{\sigma}^{\omega}$ because of severe hypercorticoid changes. Eventually prolonged high dosage produced a most striking 0 improvement but reduction because of grotesque $\omega_{\mathrm{E}}$ distortion of the face was swiftly followed by relapsec $\omega$ with fatal respiratory paralysis. In case 2 the pattep was similar, with increasing doses required \$o induce remission and severe relapse if the dose w too low. The patient developed troublesome diabetesand prolonged high doses of corticosteroids wese clearly undesirable. Guided by our experience $\frac{0}{8} \bar{D}$ case 1 the dose was reduced very gradually and on $\vec{\omega} \overrightarrow{0}$ after full return of motor power had been preseft for some months. These precautions did not prevent relapse, although its severity could be controlled. The application of this painfully acquired knowledge to the management of case 3 was frustrated by the toxic effects of prednisolone. Remission was rapid and repeated but intolerable side-effects necessitated $\mathbb{Q}$ a change to corticotrophin. This was also obviously $\overrightarrow{\overrightarrow{0}}$ effective but improvement remained critically related 3 to dosage.

It is clearly impossible to weigh the effects of treatment against the probable state of the patients if left untreated. Although in remission they were often almost free from symptons, in relapse they were far more gravely ill than when treatment was 3 begun. We are in no doubt that corticosteroid $\delta$ dependence is a highly dangerous condition. It is possible that high initial doses rather than the smallest 0 dose found to produce improvement would have been a more effective method of treatment.

In retrospect there were no features by which either the initial response to treatment or the development or of dependence could have been predicted. In Table $2 \mathrm{~N}$ the three dependent cases are compared with N six other cases fulfilling reasonably comparable 
TABLE 2

COMPARISON OF CLINICAL FEATURES OF PATIENTS SHOWING DIFFERING RESPONSES TO CORTICOSTEROID TREATMENT, SHOWING THEIR CONDITION AT THE BEGINNING OF TREATMENT

\begin{tabular}{|c|c|c|c|c|c|c|c|c|c|}
\hline Case no. & 1 & 2 & 3 & 4 & 5 & 6 & 7 & 8 & 9 \\
\hline Sex & $\mathbf{F}$ & $\mathbf{M}$ & $\mathbf{F}$ & $\mathbf{F}$ & $\mathbf{M}$ & $\mathbf{F}$ & $\mathbf{F}$ & $\mathbf{M}$ & $\mathbf{F}$ \\
\hline Age & 45 & 59 & 58 & 59 & 74 & 43 & 16 & 22 & 17 \\
\hline Duration before treatment $(\mathrm{mth})$ & 3 & 22 & 4 & 3 & 4 & 36 & 8 & 2 & 48 \\
\hline Response & D & $\mathbf{D}$ & D & $\mathbf{R}$ & $\mathbf{R}$ & $\mathbf{P}$ & $\mathbf{P}$ & $\mathbf{0}$ & $\mathbf{O}$ \\
\hline Disability & 4 & 3 & 4 & 4 & 5 & 4 & 3 & 4 & 3 \\
\hline Sensory loss & 0 & $\div$ & + & + & $\div$ & - & 0 & 0 & + \\
\hline Nerve hypert rophy & 0 & + & 0 & 0 & 0 & - & 0 & 0 & 0 \\
\hline Facial weakness & 0 & 0 & 0 & 0 & 0 & 0 & 0 & $\mathbf{0}$ & 0 \\
\hline Respiratory weakness & $\mathbf{0}$ & 0 & 0 & 0 & 0 & 0 & 0 & 0 & 0 \\
\hline CSF protein $(\mathrm{mg} / 100 \mathrm{ml})$. & 75 & 40 & 40 & 90 & 120 & 65 & 100 & 100 & 100 \\
\hline Conduciion velocity $(\mathrm{m} / \mathrm{sec})$ & 27 & 9 & 30 & 50 & 37 & 4 & 22 & 30 & 35 \\
\hline
\end{tabular}

Response: $\mathbf{D}=$ dependent $; \mathbf{R}=$ recovered; $\mathbf{P}=$ partial apparent rcsponses; $\mathbf{O}=$ no $\mathrm{r}$ ¿sponse.

Disability grading as in Fig. 1. Conduction velocity in distal segment of ulnar nerve.

criteria: no discoverable cause, a progressive stage of at least eight weeks and corticosteroid therapy equivalent to $40 \mathrm{mg}$ prednisolone a day for four weeks or such lesser dose as appeared adequate. In none of the features listed is there a consistent difference between the dependent group and those who recovered while on treatment or who showed no definite response.

The pathological changes are those commonly seen in idiopathic polyneuritis, segmental demyelination, inconstant perivascular lymphocytic infiltration, and the intraneural accumulation of eosinophilic amorphous material. The destruction of myelin by immunologically active lymphocytes suggested by Asbury et al. (1969) and the altered vascular permeability proposed by Krücke (1941) to account for the amorphous material are both processes that might be influenced by corticosteroids, but there is no evidence of any difference in pathology between those cases that respond to treatment and those that do not. Nor has it been possible to determine which aspects of the pathological process are influenced by treatment as there are obvious objections to serial nerve biopsies even if the specimens obtained were comparable. The recovery of motor power while nerve conduction is still greatly slowed has been observed during remyelination in experimental neuropathy (Morgan-Hughes, 1968), but rapid repeated changes in clinical state in response to treatment as in case 3 can only doubtfully be attributed to fluctuations in the degree of myelination. Conduction block due to oedema of the nerve trunks might be susceptible to more rapid change. The abnormal intraneural material has often been described in hypertrophic polyneuritis (Austin, 1956). It is not confined to corticosteroid-dependent or responsive cases.

We conclude that there is no clinical, electrophysiological, or histological evidence from our material that would permit the prediction of corti- costeroid dependence and that, apart from the response to treatment, there is no evidence that this is a distinct form of polyneuritis. The possible development of a state in which there may be no evasion of the dilemma of intolerable toxicity or severe paralysis should be remembered when the merits of corticosteroid treatment of chronic polyneuritis are considered.

\section{REFERENCES}

Asbury, A. K., Arnason, B. G., and Adams, R. D. (1969). The inflammatory lesion in idiopathic polyneuritis; its role in pathogenesis. Medicine (Baltimore), 48, 173-215.

Ashworth, B., and Smyth, G. E. (1969). Relapsing motor polyneuropathy. Acta. neurol. Scand., 45, 342-350.

Austin, J. H. (1956). Observations on the syndrome of hypertrophic neuritis (the hypertrophic interstitial radiculo-neuropathies). Medicine (Baltimore), 35, 187-237.

Austin, J. H. (1958). Recurrent polyneuropathies and their corticosteriod treatment. With five-year observations of a placebo-cont rolled case treated with corticotrophin, cort isone, and prednisone. Brain, 81, 157-192.

Barraine, R. (1965). Les polyradiculonévritcs autres que le syndrome de Guillain-Barré. Thèse de Paris.

Castaigne, P., Brunet, P., and Nouailhat, F. (1966). Enquête clinique sur les polyradiculonévrites inflammatoires en France. Rev. neurol., 115, 849-872.

Hinman, R. C., and Magee, K. R. (1967). Guillain-Barré syndrome with slow progressive onset and persistent elevation of spinal fluid protein. Ann. intern. Med., 67, 1007-1012.

Jean, R. G. H. (1959). Étude critique des polyradiculonévrites à rechutes. (A propos de trois cas observés dans l'enfance). Thèse de Paris.

Krücke, W. (1941). Ödem und seröse Entzündung im peripheren Nerven. Virchow's Arch. path. Anat., 308, 1-13.

Martin, J. J., and Philippart, M. (1962). Ungewöhnliche Verlaufsformen der Polyradikuloneuritis mit Liquordissoziation (Typ Guillain-Barré). Wld. Neurol., 3, 409-430.

Matthews, W. B. (1952). Cryptogenic polyneuritis. Proc. roy. Soc. Med., 45, 667-669.

Morgan-Hughes, J. A. (1968). Experimental diphtherit ic neuropathy. A pathological and electrophysiological study. J. neurol. Sci., 7 , 157-175.

Nattrass, F. J. (1921). Recurrent hypertrophic neuritis. J. Neurol. Psychopath., 2, 159-165.

Ravn, H. (1967). The Landry-Guillain-Barré syndrome. A survey and a clinical report of 127 cases. Acta neurol. Scand., 43, Suppl. 30, 1-64.

Thomas, P. K., Lascelles, R. G., Hallpike, J. F., and Hewer, R. L. (1969). Recurrent and chronic relapsing Guillain-Barré polyneurit is. Brain, 92, 589-606. 